\title{
Preparation, Characterization and Photostability of Nanocomposite Films Based on Poly(acrylic acid) and Montmorillonite
}

\author{
Virgínia de Alencar Muniz Gonzaga ${ }^{a}$, Bruno Alvim Chrisostomo ${ }^{a}$, Alessandra Lima Polia,
}

\author{
Carla Cristina Schmitt * (1)
}

\author{
anstituto de Química de São Carlos, Universidade de São Paulo, Av. Trab. São-Carlense, 400, 13566- \\ 590, São Carlos, SP, Brasil
}

Received: November 20, 2017; Revised: January 22, 2018; Accepted: March 08, 2018

\begin{abstract}
Polyacrylic acid (PAA)/clay mineral (SWy-1) nanocomposites were prepared by intercalation in solution and their photostability was evaluated. For the nanocomposite films containing 5, 10 and $20 \mathrm{wt}$ $\%$ in SWy-1 mass occurred intercalation along with some clay exfoliation, while for PAA $30 \% \mathrm{SWy}-1$, the intercalation of PAA chains into the clay interlayers was observed. Scanning Electron Microscopy (SEM) images of the films suggested that nanocomposite films are homogeneous, indicating efficient dispersion of the polymer matrix into the SWy-1 clay. The thermal degradation temperatures of depolymerisation for the nanocomposite films were higher $\left(362-370{ }^{\circ} \mathrm{C}\right)$ than pure PAA $\left(361{ }^{\circ} \mathrm{C}\right)$, which means that the presence of SWy-1 clay promotes thermal stabilization. The photooxidative degradation of pure PAA and nanocomposite films was followed using Size Exclusion Chromatography (SEC). The degradation rate constant for pure PAA was higher than nanocomposite films; therefore, the increase of SWy-1 concentration detained the degradation of PAA. The presence of SWy-1 clay contributes for the photostabilization of the material. SWy-1 has ability to disperse the incident light as well as also to absorb part of the UV light instead of PAA, hence minimizing the degradation rate.
\end{abstract}

Keywords: Clay, Poly(acrylic acid), Nanocomposites, Photodegradation.

\section{Introduction}

In recent years, polymer layered silicate nanocomposites have attracted attention in many fields, e.g., in industry exploitation and fundamental research ${ }^{1,2}$. These materials exhibit excellent mechanical and thermal properties, decrease in gas/vapor permeability, and reduced flammability in the presence of a small amount of the silicate, as compared with the polymer itself ${ }^{2-4}$.

Clay minerals are materials of natural origin, with particles smaller than $2 \mu \mathrm{m}$. Among clays, montmorillonite (Mt) is one of the most commonly used and extensively studied of clay mineral polymer nanocomposites ${ }^{5,6}$. It pertains to the general family of 2:1 layered silicates made up of two silica tetrahedral sheets merged to an edge-shared octahedral sheet of magnesia or alumina. The stacking of these layers occurs in a parallel way, thus leading to a regular van der Waals gap between the layers called the interlayer region ${ }^{7,8}$.

Complementary to the aforementioned properties, $\mathrm{Mt}$ is also widely available and an inexpensive material. It presents a large swelling behavior due to its expanded surface area leading to potential strong interactions between polymer matrix and clay mineral. Thereby, the combination of all those characteristics results in intercalated and exfoliated structures of the clay mineral polymer nanocomposites ${ }^{9,10}$.
Poly(acrylic acid) (PAA) is a water soluble polymer and it belongs to a class of commercial polymers produced on a large scale and PAA has been used for applications in $\mathrm{Cu}$ (II) removal from aqueous solutions ${ }^{11,12}$, drug delivery applications ${ }^{13}$, as cleaning agents ${ }^{14}$ and medicine ${ }^{15,16}$.

The dispersion of the Mt in the polymeric matrix depends on the process used in the preparation of the nanocomposites, clay and polymer type, and the interaction between both (clay mineral and polymer) $^{17}$.

The polymer materials photodegradation is a concern in their process and usage, even in polymer layered silicate nanocomposites, as a consequence, it has been a subject of studies $^{18,19}$. Thus, it is necessary to gain a better understanding of degradation and stabilization to ensure long life for the product, since this process for this nanocomposite is poorly understood.

Herein, PAA nanocomposites with clay mineral were prepared by intercalation in solution and characterized by Fourier transform infrared spectroscopy (FTIR), X-ray diffraction (XRD), scanning electron microscopy (SEM) and thermogravimetric analysis (TGA). Furthermore, the photostability of clay mineral polymer nanocomposites films was studied, because it knows that load of polymer by layered filler changes the interactions into the polymeric matrix, which can affect nanocomposite resistance to UV radiation ${ }^{8}$. 


\section{Materials and Methods}

\subsection{Materials}

Poly(acrylic acid) was purchased from Sigma Aldrich. The SWy-1 montmorillonite was kindly supplied by Source Clays Repository of the Clay Minerals Society, University of Missouri, Columbia, MO. The Mt was purified as described earlier $^{20}$

\subsection{Nanocomposite films preparation}

A Poly(acrylic acid) aqueous solution of $1.0 \%(\mathrm{w} / \mathrm{v})$ was prepared by dissolving $1.0 \mathrm{~g}$ of PAA powder in $100 \mathrm{~mL}$ of distilled water. SWy-1 Mt (SWy-1) dispersions were prepared by dispersing appropriate amounts of $\mathrm{Mt}$ into distilled water and both were vigorously stirring for $24 \mathrm{~h}$.

Nanocomposite films with SWy-1 were made by mixing PAA aqueous solution with the right amounts of SWy-1 dispersion based on PAA: $5 \mathrm{wt} \%$ (PAA/5\%SWy-1), $10 \mathrm{wt}$ $\%$ (PAA/10\% SWy-1), 20 wt \% (PAA/20\% SWy-1) and 30 wt \% (PAA/30\% SWy-1).

The mixtures were stirred continuously and then cast onto glass Petri dishes. The films were dried in an oven at $37^{\circ} \mathrm{C}$ for $24 \mathrm{~h}$ and peeled from the glass Petri dishes. For comparison, the pure PAA films were prepared in the same way.

\subsection{Characterization}

The X-ray diffraction (XRD) was used to determine the structure of nanocomposite films using, a RigakuRotaflex - RU 200B diffractometer $(\mathrm{Cu}$, radiation $\lambda=0.154 \mathrm{~nm})$ at $50 \mathrm{kV}, 100 \mathrm{~mA}$. The interlayer space of the samples was calculated using Bragg's equation ${ }^{21}$.

The surface morphology of nanocomposite films was examined by scanning electron microscopy (SEM) using 20 keV energy ZEISS LEO 440 equipment with an OXFORD $20 \mathrm{kV}$ detector at $2.7 \times 10^{-6}$ torr.

The TGA curves for PAA and nanocomposite films were obtained in a SDT-Q 600 TG/DTA simultaneous module (TA Instruments, Shimadzu). The curves were obtained under a dynamic air atmosphere and heated from $25^{\circ} \mathrm{C}$ to $1000^{\circ} \mathrm{C}$ at a heating rate of $10^{\circ} \mathrm{C} / \mathrm{min}$. The thermal measurements were carried out under air atmosphere with flow rate of $60 \mathrm{~mL} \mathrm{~min}^{-1}$.

\subsection{Photodegradation of nanocomposite films by UV Irradiation}

Nanocomposite films were exposed at $40{ }^{\circ} \mathrm{C}$ in an irradiation chamber containing 16 UV germicidal lamps, emitting light predominantly at $254 \mathrm{~nm}$. The SPR-01 Spectroradiometer (Luzchem) was used to measure the emission of the lamp. The emission spectrum of the lamps is presented in Figure 1, along with the UV-vis spectra of SWy-1, PAA and nanocomposite films. The absorption of SWy-1 at $241 \mathrm{~nm}$ is attributed to a charge transfer transition from $\left(\mathrm{Fe}^{+3}\right)$ located in the Mt layers ${ }^{22}$.

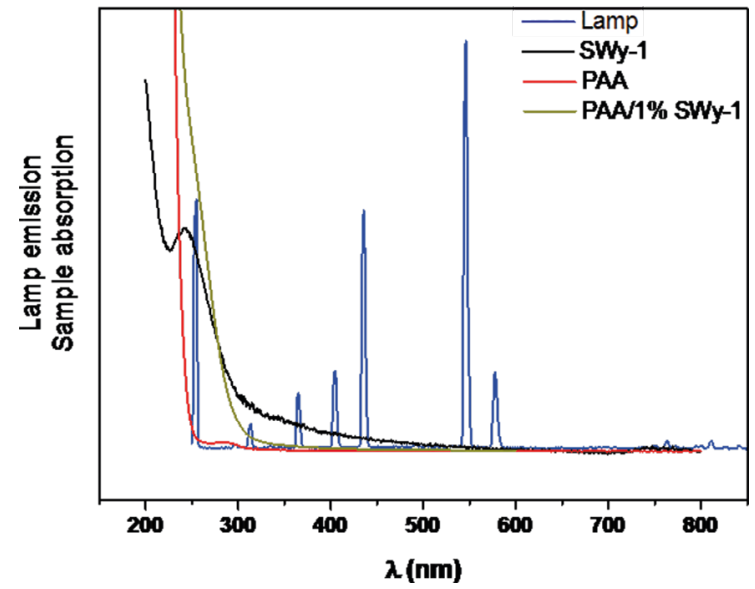

Figure 1. Emission spectra of irradiating lamp and absorption spectra of SWy-1, PAA and nanocomposite films

Photodegradation was monitored by Fourier transform infrared spectroscopy, FTIR spectra were recorded using a Perkin-Elmer Frontier spectrometer using a universal attenuated total reflectance (ATR) sampling accessory. All spectra were recorded in absorption mode at $1 \mathrm{~cm}^{-1}$ intervals and 32 scans.

Size exclusion chromatography (SEC) was performed at $35^{\circ} \mathrm{C}$ on a Shimadzu LC-20 AD chromatographic system with a Shimadzu RID-10A refractive index detector, using three OHpak KB-806M columns, narrow-distribution PEO standards were used for calibration. Irradiated film samples were dissolved in sodium nitrate solution $0.1 \mathrm{~mol} \mathrm{~L}^{-1}$ and aliquots $(2 \mathrm{~mL})$ were filtered through $0.45 \mu \mathrm{m}$ membranes before analysis. The same solution was used as the eluent at a flow rate of $1 \mathrm{~mL} \mathrm{~min}{ }^{-1}$.

\section{Results and Discussion}

\subsection{Characterization of nanocomposite films}

The XRD patterns were used to calculate the d001value and to study the structure of the nanocomposite with different amounts of SWy-1. Figure 2 shows the results of XRD for PAA, SWy-1 and nanocomposite films. The polymer incorporation in the SWy-1 dispersion shifted the 001 reflection peak from $7.5^{\circ}$ to $4.3-4.6^{\circ}$, suggesting the occurrence of intercalation (PAA molecules may enter between silicate layers) for all concentrations of SWy-1. And this main peak in the XRD pattern of SWy-1 $(2 \theta \sim 7.5$ ${ }^{\circ}$ ) corresponds to an interlayer distance of $11.8 \AA$ and it is attributed to the formation of interlayer spaces by regular stacking of the silicate layers along the [001] direction ${ }^{12,23,24}$.

For the nanocomposite films containing 5, 10 and $20 \mathrm{wt} \%$ in SWy-1 mass, there is a lower and wider 001 reflection peak than pure SWy-1, indicating the occurrence of intercalation along with some clay exfoliation ${ }^{18,25}$ 


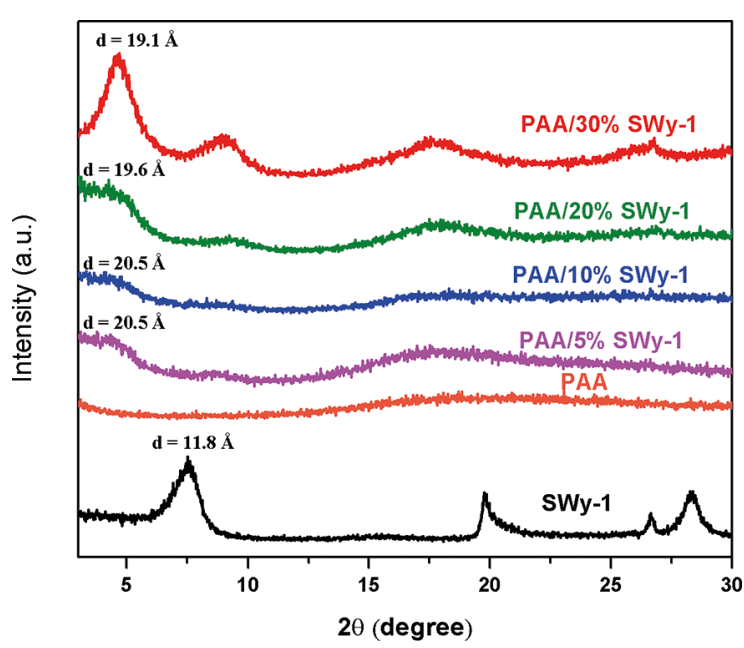

Figure 2. X-ray diffraction for SWy-1 clay, PAA and nanocomposite films.

On the other hand, the 001 reflection peak for PAA $/ 30 \%$ SWy-1 has been shifted toward lower angles, which is an indication of the lower regularity and large basal spacing as a result of the intercalation of PAA chains into the clay galleries ${ }^{26}$.

Figure 3 presents FTIR-ATR spectra of PAA, SWy-1 and PAA $/ 5 \%$ SWy- 1 nanocomposite film. SWy-1 spectrum shows characteristic band at $3626 \mathrm{~cm}^{-1}$ due to a hydroxyl group bound with $\mathrm{Al}^{3+}$ cations ${ }^{27}$. The stretching and bending vibrations of $\mathrm{O}-\mathrm{H}$ of water molecules present in the clay are observed at 3422 and $1638 \mathrm{~cm}^{-1}$, respectively. The most intensive and narrow band is noticed at $996 \mathrm{~cm}^{-1}$ and it is attributed to $\mathrm{Si}-\mathrm{O}$ stretching vibrations. The three bands below $996 \mathrm{~cm}^{-1}$ originate from bending vibrations of AlAlOH $\left(914 \mathrm{~cm}^{-1}\right), \mathrm{AlFeOH}\left(884 \mathrm{~cm}^{-1}\right)$ and AlMgOH $\left(798 \mathrm{~cm}^{-1}\right)^{27,28}$. The typical structure of PAA exhibits a broad absorption band at $3056 \mathrm{~cm}^{-1}$ due to the $-\mathrm{OH}$ stretching vibration, it has a characteristic band at $1700 \mathrm{~cm}^{-1}$ attributed to $\mathrm{C}=\mathrm{O}$ stretching. The band at $1200-1315 \mathrm{~cm}^{-1}$ is related to the C-O stretch. The band at $1395-1450 \mathrm{~cm}^{-1}$ is assigned to C-O-H deformation vibration. Absorption band at $792 \mathrm{~cm}^{-1}$ is due to out-of-plane $\mathrm{OH}$...O deformation, indicating the existence of strong inter-chain hydrogen bonds ${ }^{29,30}$. FTIR-ATR spectrum of PAA $/ 5 \% \mathrm{SWy}-1$ is the combination of the characteristics bands of the spectra of both components, the band at 1700 $\mathrm{cm}^{-1}$ is connected with the stretching vibrations of $\mathrm{C}=\mathrm{O}$ in carboxyl group. Absorption maxima at 1450 and $1412 \mathrm{~cm}^{-1}$ are characteristic of asymmetric and symmetric stretching vibrations of $\mathrm{C}-\mathrm{O}$ bonds in carboxyl groups.

Figure 4 shows SEM images of the films (PAA/ $10 \% \mathrm{SWy}-1$ and $\mathrm{PAA} / 30 \% \mathrm{SWy}-1)$ and these images suggest that nanocomposite films are homogeneous, indicating efficient dispersion of the polymer matrix into the SWy-1 clay. Most of separate and flat clay platelets are dispersed uniformly on

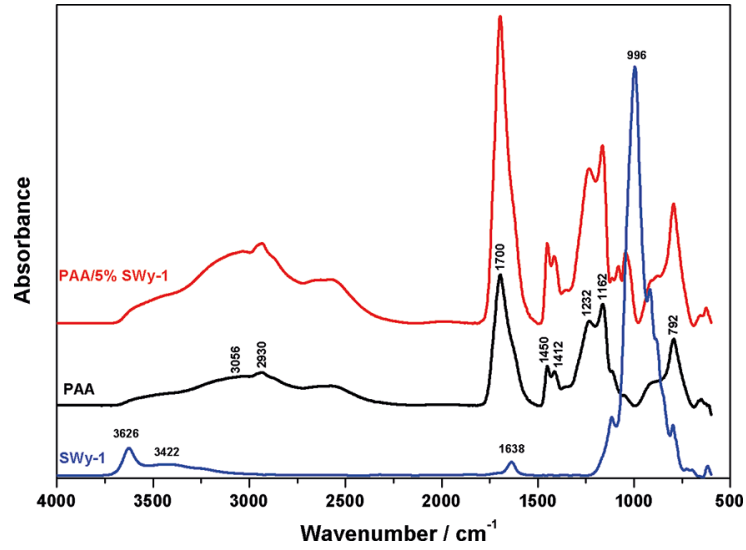

Figure 3. FTIR-ATR spectra of SWy-1, PAA and PAA/5\%SWy-1 nanocomposite film.

the surface of the film. The amount of SWy-1 particles on the surface of the PAA $/ 30 \%$ SWy- 1 is more than PAA $/ 10 \% \mathrm{SWy}-1$ nanocomposite film. In addition, the image of cross section (Figure 4c) shows the thickness of the films was 65 to $70 \mu \mathrm{m}$.

For estimation of thermal stability, all samples were subjected thermogravimetric analysis at air atmosphere. The results obtained for PAA and nanocomposite films are presented in Figure 5. The PAA thermal degradation process is divided in several stages ${ }^{28,29}$. The first stage $\left(70-173^{\circ} \mathrm{C}\right)$ is the removal of the water physically absorbed. In the second stage $\left(173-310{ }^{\circ} \mathrm{C}\right)$, the carboxyl side groups underwent decomposition. The third stage $\left(310-410{ }^{\circ} \mathrm{C}\right)$ resulted in oxidation of carbon backbone chains (depolymerization). A further increase in temperature only $\mathrm{H}_{2} \mathrm{O}$ and $\mathrm{CO}_{2}$ are released, indicating the complete oxidation.

The thermal degradation temperatures in the third stage for the nanocomposite films were higher $\left(362-370^{\circ} \mathrm{C}\right)$ than pure PAA $\left(361^{\circ} \mathrm{C}\right)$, which means that the presence of SWy-1 clay shifted the depolymerization process (third step) toward a higher temperature indicating the nanocomposites are more thermally stable when compared to PAA itself.

\subsection{Photodegradation of nanocomposite films}

PAA and nanocomposite films were irradiated with UV light up to $192 \mathrm{~h}$ at $40^{\circ} \mathrm{C}$. UV irradiation of PAA/SWy-1 films causes significant changes in FTIR spectra, which are presented in Figure 6.

For the qualitative evaluation of nanocomposites photodegradation, the carbonyl band $\left(1600-1800 \mathrm{~cm}^{-1}\right)$ was applied. This band undergoes broadening during irradiation, but absorbance maximum $\left(1698 \mathrm{~cm}^{-1}\right)$ decreases. This is the evidence of the occurrence of two opposite reactions: abstraction (or destruction) of carboxylic groups and macrochain oxidation leading to the formation of a new type of carbonyl groups in the film ${ }^{26,30}$. The general mechanism for leading to the destruction of this group during the photodegradation of PAA is shown schematically in Figure $7^{31}$. 

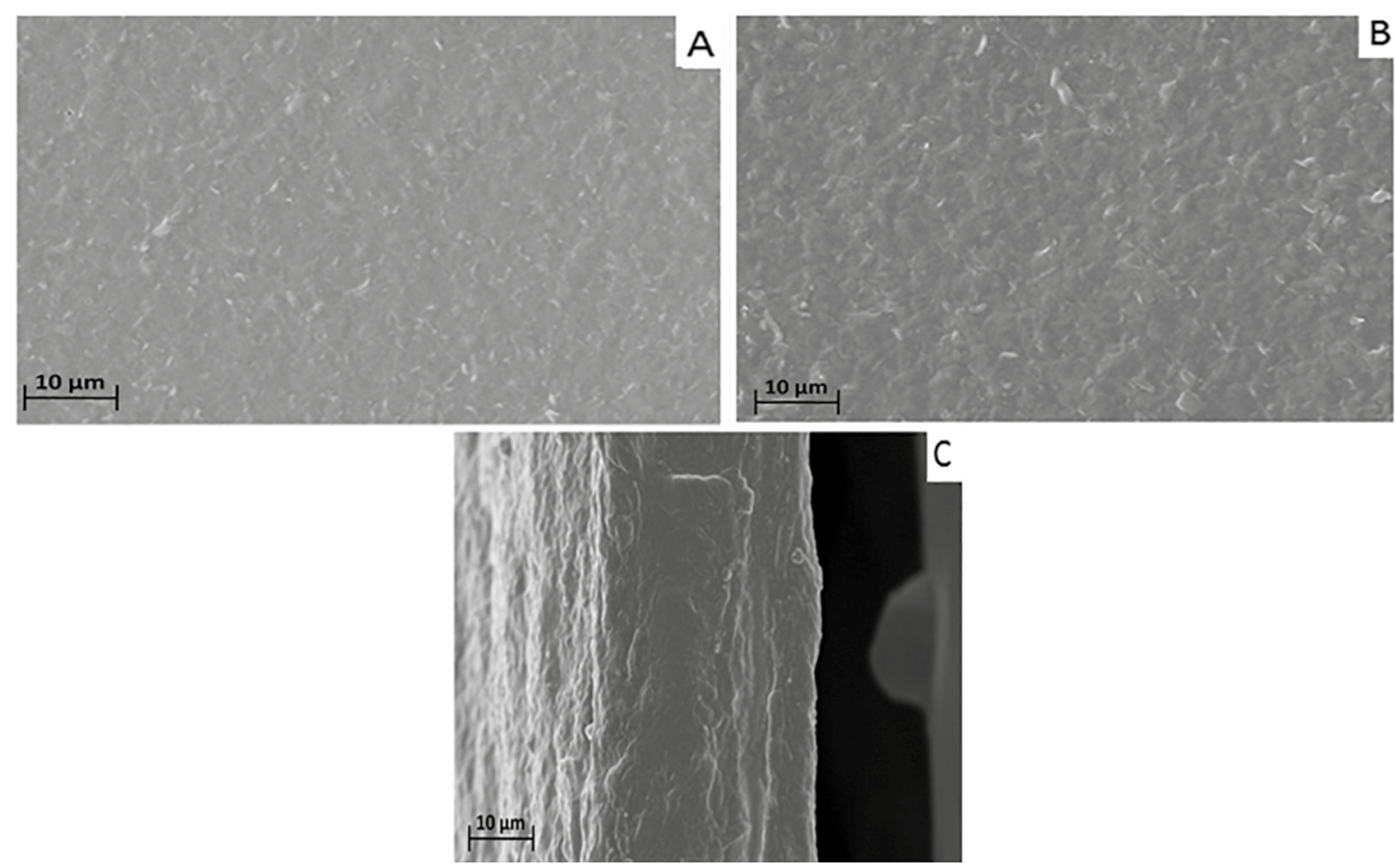

Figure 4. SEM images of (a) PAA $/ 10 \% \mathrm{SWy}-1$ and (b) PAA $/ 30 \%$ SWy-1, transversal section of the nanocomposite film (c) PAA $/ 30 \% \mathrm{SWy}-1$.
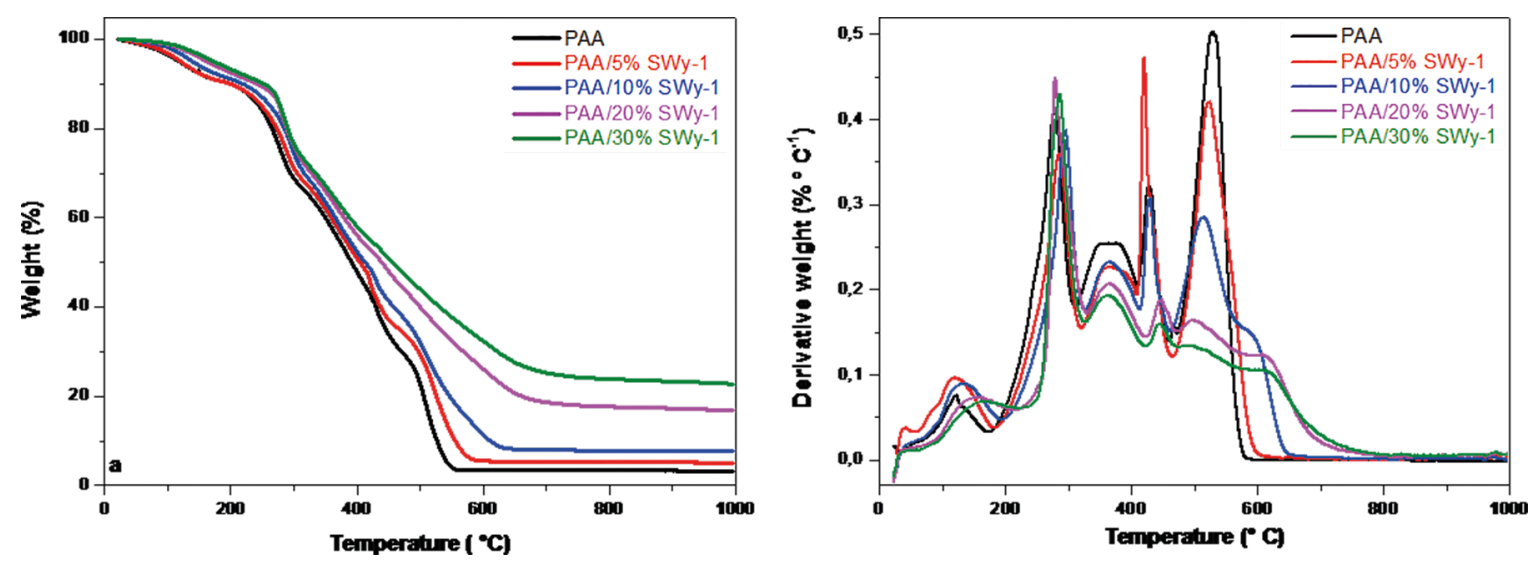

Figure 5. TGA and DTG curves for PAA and nanocomposite films.
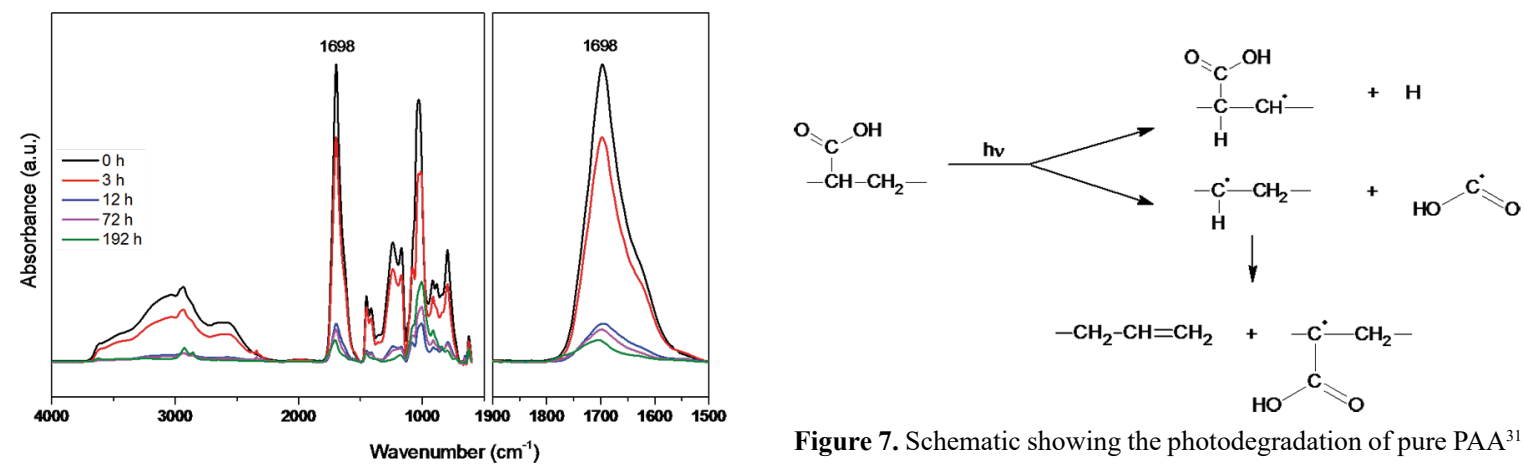

Figure 6. FTIR-ATR spectra of PAA/ $30 \% \mathrm{SWy}-1$ nanocomposite film as a function of irradiation time.

Figure 7. Schematic showing the photodegradation of pure PAA ${ }^{31}$ 
The photooxidative degradation of pure PAA and nanocomposite films was followed using SEC.

According to Kaczmarek et al., the radicals formed during UV irradiation of PAA may interact with the polysaccharide chain, resulting in its rupture, $\mathrm{COOH}$ abstraction and may interact with other radicals to form crosslinks between chain ${ }^{30}$.

Molecular weight $\left(\overline{M_{w}}\right)$ of the nanocomposite films decreased after $12 \mathrm{~h}$ of irradiation (Figure 8). SEC results suggested that PAA and nanocomposite films degrade by random chain scissions ${ }^{32}$.

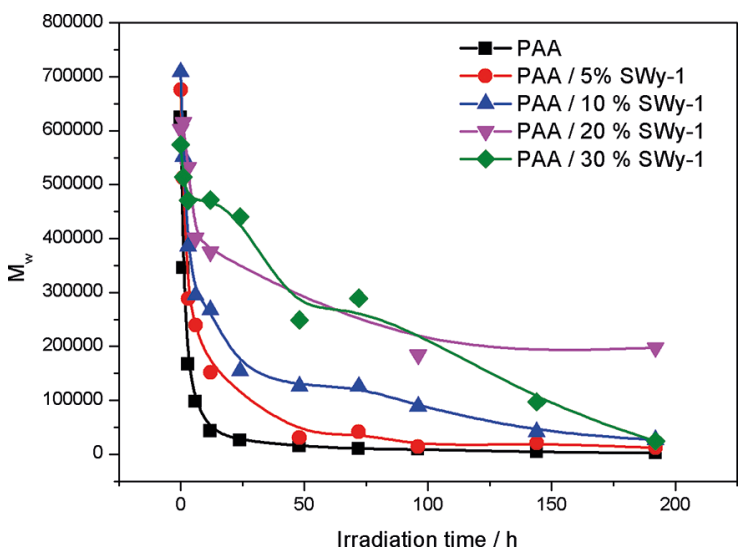

Figure 8. Decrease in molecular weight $\left(\overline{M_{w}}\right)$ during photodegradation of PAA and nanocomposite films.

Marimuthu and Madras (2007) proposed a model for polymer degradation in which it is possible to determine the degradation rate constant $k_{d}^{33}$. This constant is obtained using a variation of number-average molecular weight $\left(\overline{M_{n}}\right)$ with time (Equation 1).

$$
\frac{\overline{M_{n}}(0)}{\overline{M_{n}}(t)}-1=\overline{M_{n}}(0) k_{d} t
$$

The plot of the $\left(\overline{M_{n}}\right)$ behaviour for all samples as a function of irradiation time was presented in Figure 9, from the initial slopes of curves (Figure 9b) was determined the degradation rate constants, $k_{d}$, and the values are shown in Table 1.
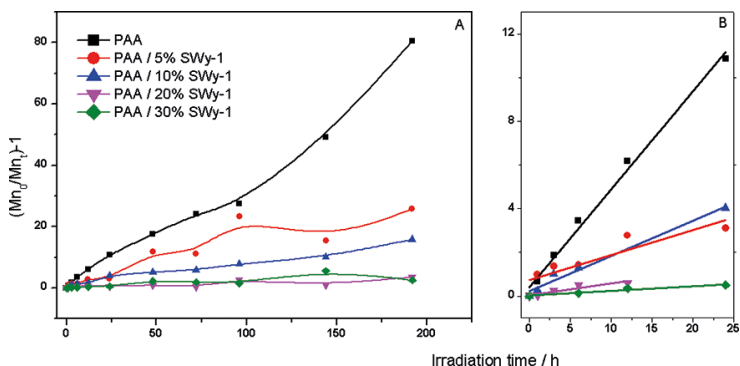

Figure 9. (a) Variation of $\left[\overrightarrow{M_{n}}(0) / \overrightarrow{M_{n}}(\mathrm{t})\right]-1$ as a function of irradiation time for chitosan and nanocomposite films; (b) blow up of the initial times.
Table 1. Initial Number Average Molecular Weights and photodegradation rates of PAA and nanocomposite films.

\begin{tabular}{lcc}
\hline Samples & $\bar{M}_{n}$ & $k_{d}\left(10^{-7} \mathrm{~mol} \mathrm{~g}^{-1} \mathrm{n}^{-1}\right)$ \\
\hline PAA & 156,000 & 29.0 \\
PAA $/ 5 \%$ SWy-1 & 156,800 & 7.3 \\
PAA $/ 10 \%$ SWy-1 & 173,000 & 9.3 \\
PAA $/ 20 \%$ SWy-1 & 116,200 & 4.7 \\
PAA/30\%SWy-1 & 126,800 & 1.3 \\
\hline
\end{tabular}

The degradation rate constant for pure PAA was up to 22 times higher in relation to the nanocomposite with 30 wt $\%$ of SWy- 1 content; therefore, the increase of SWy-1 concentration detained the degradation of PAA.

Owing to the degradation rate, the SWy-1 might be considered as stabilizer against UV irradiation. Thereby, this stabilization can be explained by SWy-1 ability to disperse the incident light in addition to its absorbtion part of the UV light instead of PAA, hence minimizing the degradation rate ${ }^{18,34}$.

Some studies in the literature describe the stabilization of polymer degradation promoted by clay mineral. This behavior was observed for nanocomposite degradation of $\mathrm{PEO} /$ clay, $\mathrm{PVC} /$ laponite and chitosans/montmorillonite ${ }^{8,18,35}$.

SEC results indicated that the amount of Mt in the nanocomposite influenced the material's photostability.

\section{Conclusions}

PAA/clay nanocomposites present exfoliated and/or intercalated structures depending the amount of clay used. The nanocomposite films presented a homogeneous surface as it was shown by SEM images. Moreover, the nanocomposite films demonstrated an enhanced thermal stability compared to the pure polymer.

The presence of clay detains the fast photo-oxidation of the nanocomposites and decreases the main chain scission process. The degradation rate constant for pure PAA was up to 22 times larger in relation to the nanocomposite with higher amount of SWy-1. Thus, the presence of SWy-1 clay contributes for the photostabilization of material. SWy-1 has ability to disperse the incident light as well as also to absorb part of the UV light instead of PAA. Such evidence bolsters the effect of SWy-1 in the stabilization against UV irradiation.

\section{Acknowledgements}

The authors would like to thank FAPESP (2012/19656-0) and CNPq (490421/2013-0, 401434/2014-1 and 308940/20130 ) for their financial support. The authors would also like to thank Dr. Marco Horn for the thermogravimetric analysis. 


\section{References}

1. Sahoo BP, Tripathy DK. Introduction to Clay- and CarbonBased Polymer Nanocomposites: Materials, Processing, and Characterization. In: Tripathy DK, Sahoo BP, eds. Properties and Applications of Polymer Nanocomposites: Clay and Carbon Based Polymer Nanocomposites. Berlin, Heidelberg: Springer; 2017. p. 1-24.

2. Giannakas A, Grigoriadi K, Leontiou A, Barkoula NM, Ladavos A. Preparation, characterization, mechanical and barrier properties investigation of chitosan-clay nanocomposites. Carbohydrate Polymers. 2014;108:103-11.

3. Müller K, Bugnicourt E, Latorre M, Jorda M, Echegoyen Sanz Y, Lagaron JM, et al. Review on the Processing and Properties of Polymer Nanocomposites and Nanocoatings and Their Applications in the Packaging, Automotive and Solar Energy Fields. Nanomaterials (Basel). 2017;7(4):E74.

4. Guo J, Xu Y, Chen X, Hu S, He M, Qin S. Influences of organic montmorillonite on the combustion behaviors and thermal stability of polyamide 6/polystyrene blends. High Performance Polymers. 2015;27(4):392-401.

5. Bergaya F, Lagaly G, eds. Handbook of Clay Science. Amsterdam: Elsevier; 2013.

6. Chatel G, Novikova L, Petit S. How efficiently combine sonochemistry and clay science? Applied Clay Science. 2016;119(Pt 2):193-201.

7. Hong SI, Lee JH, Bae HJ, Koo SY, Lee HS, Choi JH, et al. Effect of shear rate on structural, mechanical, and barrier properties of chitosan/montmorillonite nanocomposite film. Journal of Applied Polymer Science. 2011;119(5):2742-2749.

8. Lombardo PC, Poli AL, Neumann MG, Machado DS, Schmitt CC. Photodegradation of poly(ethyleneoxide)/montmorillonite composite films. Journal of Applied Polymer Science. 2013;127(5):3687-3692.

9. Farshi Azhar F, Olad A, Mirmohseni A. Development of novel hybrid nanocomposites based on natural biodegradable polymermontmorillonite/polyaniline: preparation and characterization. Polymer Bulletin. 2014;71(7):1591-1610.

10. Sengwa RJ, Choudhary S. Structural characterization of hydrophilic polymer blends/montmorillonite clay nanocomposites. Journal of Applied Polymer Science. 2014;131(16):40617.

11. Yan H, Yang L, Yang Z, Yang H, Li A, Cheng R. Preparation of chitosan/poly(acrylic acid) magnetic composite microspheres and applications in the removal of copper(II) ions from aqueous solutions. Journal of Hazardous Materials. 2012;229-230:371380 .

12. Rafiei HR, Shirvani M, Ogunseitan OA. Removal of lead from aqueous solutions by a poly(acrylic acid)/bentonite nanocomposite. Applied Water Science. 2016; 6(4):331-338.

13. Müller C, Leithner K, Hauptstein S, Hintzen F, Salvenmoser W, Bernkop-Schnürch A. Preparation and characterization of mucus-penetrating papain/poly(acrylic acid) nanoparticles for oral drug delivery applications. Journal of Nanoparticle Research. 2013;15:1353.
14. Carretti E, Dei L, Baglioni P. Aqueous polyacrylic acid based gels: physicochemical properties and applications in cultural heritage conservation. In: Miguel M, Burrows HD, eds. Trends in Colloid and Interface Science XVI. Berlin, Heidelberg: Springer; 2004. p. 280-283.

15. Jones $\mathrm{CF}$, Grainger DW. In vitro assessments of nanomaterial toxicity. Advanced Drug Delivery Reviews. 2009;61(6):438-456.

16. Cabana S, Lecona-Vargas CS, Meléndez-Ortiz HI, ContrerasGarcía A, Barbosa S, Taboada P, et al. Silicone rubber films functionalized with poly(acrylic acid) nanobrushes for immobilization of gold nanoparticles and photothermal therapy. Journal of Drug Delivery Science and Technology. 2017;42:245-254.

17. Echeverría I, Eisenberg P, Mauri AN. Nanocomposites films based on soy proteins and montmorillonite processed by casting. Journal of Membrane Science. 2014; 449:15-26.

18. Gabriel JS, Gonzaga VAM, Poli AL, Schmitt CC. Photochemical synthesis of silver nanoparticles on chitosans/montmorillonite nanocomposite films and antibacterial activity. Carbohydrate Polymers. 2017;171:202-210.

19. La Mantia FP, Morreale M, Botta L, Mistretta MC, Ceraulo M, Scaffaro R. Degradation of polymer blends: A brief review. Polymer Degradation and Stability. 2017;145:79-92.

20. Gessner F, Schmitt CC, Neumann MG. Time-Dependent Spectrophotometric Study of the Interaction of Basic Dyes with Clays. I. Methylene Blue and Neutral Red on Montmorillonite and Hectorite. Langmuir. 1994;10(10):3749-3753.

21. Callister WD Jr, Rethwisch DG. Materials Science and Engineering: An Introduction. New York: Wiley; 2007.

22. Karickhoff SW, Bailey GW. Optical Absorption Spectra of Clay Minerals. Clays and Clay Minerals. 1973;21(1):59-70.

23. Tran NH, Dennis GR, Milev AS, Kannangara GSK, Wilson MA, Lamb RN. Interactions of sodium montmorillonite with poly(acrylic acid). Journal of Colloid and Interface Science. 2005;290(2):392-396.

24. Natkanski P, Kustrowski P, Bialas A, Wach A, Rokicinska A, Kozak M, et al. Hydrogel template-assisted synthesis of nanometric $\mathrm{Fe}_{2} \mathrm{O}_{3}$ supported on exfoliated clay. Microporous and Mesoporous Materials. 2016;221:212-219.

25. Xu Y, Ren X, Hanna MA. Chitosan/clay nanocomposite film preparation and characterization. Journal of Applied Polymer Science. 2006;99(4):1684-1691.

26. Zhang Y, Gu Q, Dong Z, He P. Effect of Reaction Parameters on Swelling Properties of Poly (Acrylic Acid-Acrylamide/ Montmorillonite) Nanocomposite Superabsorbents. PolymerPlastics Technology and Engineering. 2012;51(4):407-412.

27. Paluszkiewicz C, Stodolak E, Hasik M, Blazewicz M. FT-IR study of montmorillonite-chitosan nanocomposite materials. Spectrochimica Acta Part A: Molecular and Biomolecular Spectroscopy. 2011;79(4):784-788.

28. Natkanski P, Kustrowski P, Bialas A, Surman J. Effect of $\mathrm{Fe}^{3+}$ ions present in the structure of poly(acrylic acid)/montmorillonite composites on their thermal decomposition. Journal of Thermal Analysis and Calorimetry. 2013;113(1):335-342. 
29. Dubinsky S, Grader GS, Shter GE, Silverstein MS. Thermal degradation of poly(acrylic acid) containing copper nitrate. Polymer Degradation and Stability. 2004;86(1):171-178.

30. Kaczmarek H, SzallaA. Photochemical transformation in poly(acrylic acid)/poly(ethylene oxide) complexes. Journal of Photochemistry and Photobiology A: Chemistry. 2006;180(1-2):46-53.

31. Kaczmarek H, Kaminska A, Swiatek M, Rabek JF. Photooxidative degradation of some water-soluble polymers in the presence of accelerating agents. Macromolecular Materials and Engineering. 1998;261-262(1):109-121.

32. Kaczmarek H, Kaminska A, van Herk A. Photooxidative degradation of poly(alkyl methacrylate)s. European Polymer Journal. 2000;36(4):767-777.
33. Marimuthu A, Madras G. Effect of Alkyl-Group Substituents on the Degradation of Poly(alkyl methacrylates) in Supercritical Fluids. Industrial and Engineering Chemistry Research. 2007;46(1):15-21.

34. Oliveira CFP, Carastan DJ, Demarquette NR, Fechine GJM. Photooxidative behavior of polystyrene-montmorillonite nanocomposites. Polymer Engineering \& Science. 2008;48(8):15111517.

35. Essawy HA, Abd El-Wahab NA, Abd El-Ghaffar MA. PVClaponite nanocomposites: Enhanced resistance to UV radiation. Polymer Degradation and Stability. 2008;93(8):1472-1478. 